\title{
NBSIR 79-1736
}

\section{Evaluation of Hand-Held Infrared Thermometers for Wall Thermal Resistance Determinations}

Stephen J. Treado

Douglas M. Burch

Building Thermal and Service Systems Division

Center for Building Technology

National Engineering Laboratory

National Bureau of Standards

July 1979
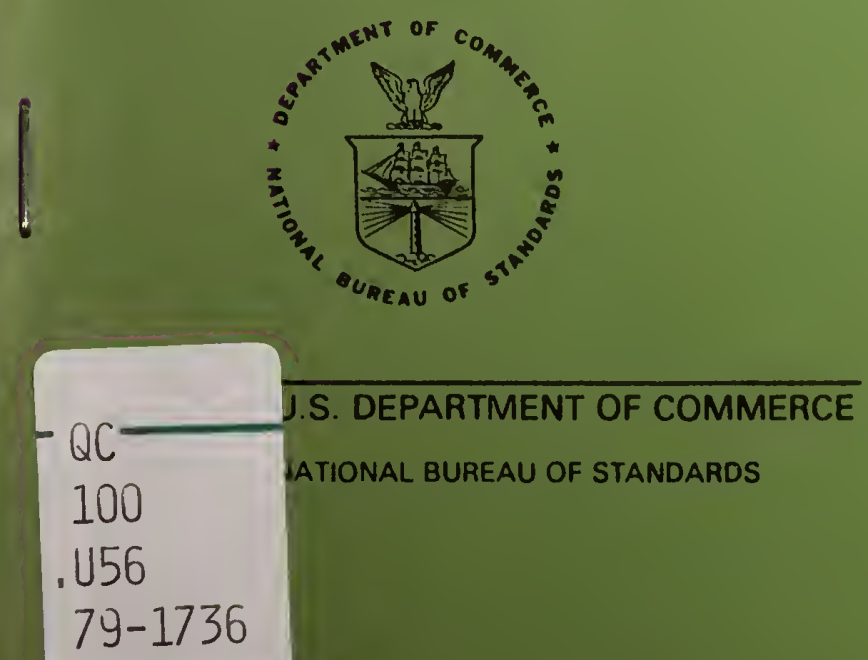
EVALUATION OF HAND-HELD

INFRARED THERMOMETERS FOR WALL

THERMAL RESISTANCE

DETERMINATIONS

Stephen J. Treado

Douglas M. Burch

Building Thermal and Service Systems Division

Center for Building Technology

National Engineering Laboratory

National Bureau of Standards

July 1979

U.S. DEPARTMENT OF COMMERCE, Juanita M. Kreps, Secretary

Luther H. Hodges, Jr., Under Secretary

Jordan J. Baruch, Assistant Secretary for Science and Technology

NATIONAL BUREAU OF STANDARDS, Ernest Ambler, Director 

Hand-held infrared (IR) non-contact surface thermometers from two manufacturers were tested to evaluate their effectiveness in measuring surface temperatures for the determination of the thermal resistance of walls. Two phases of the test were performed, first a laboratory test of a wood-frame wall, followed by a field test of a brick veneer wood-frame wall. During both phases of testing, additional measurements of thermal resistance were made for comparative purposes, using multijunction thermopiles and heat-flow meters. An error analysis of the thermal resistance measurement procedure utilizing IR surface thermometers was also performed.

Key words: Infrared thermometers; in situ evaluation of insulation; $R$-value measurement by spot radiometer; thermal resistance of walls. 
ABSTRACT $\ldots \ldots \ldots \ldots \ldots \ldots \ldots \ldots \ldots \ldots \ldots \ldots \ldots \ldots \ldots \ldots \ldots \ldots \ldots \ldots \ldots \ldots \ldots \ldots \ldots$

1. INTRODUCTION .................................

2. THERMAL RESISTANCE DETERMINATION TECHNIQUE ............

3. EXPERIMENTAL PLAN ............................

4. LABORATORY TEST ...............................

4.1 Instrumentation and Test Set-up ...................

4.2 Measurement Procedure ............................

4.3 Experimental Results ...........................

5. FIELD TEST $\ldots \ldots \ldots \ldots \ldots \ldots \ldots \ldots \ldots \ldots \ldots \ldots \ldots \ldots \ldots \ldots \ldots \ldots \ldots \ldots \ldots \ldots \ldots \ldots$

5.1 Instrumentation and Test set-up .................. 11

5.2 Measurement Procedure .......................... 11

5.3 Experimental Results .......................... 13

6. ANALYSIS ......................................... 14

7. SUMMARY $\ldots \ldots \ldots \ldots \ldots \ldots \ldots \ldots \ldots \ldots \ldots \ldots \ldots \ldots \ldots \ldots \ldots \ldots \ldots \ldots \ldots \ldots \ldots \ldots$

NOMENCLATURE ........................................ 20

SI CONVERSION CHART $\ldots \ldots \ldots \ldots \ldots \ldots \ldots \ldots \ldots \ldots \ldots \ldots \ldots \ldots \ldots \ldots \ldots \ldots \ldots \ldots$ 
Evaluation of Hand-held Infrared Thermometers

for Wall Thermal Resistance Determinations

\author{
by \\ Stephen J. Treado \\ and \\ Douglas M. Burch
}

\title{
1. INTRODUCTION
}

Recently a technique was introduced for determining the thermal resistance of walls through the use of hand-held infrared thermometers. These devices are also known as spot radiometers or hand-held non-contact temperature indicators. A controversial issue is whether these devices can be used effectively for this purpose. This paper attempts to evaluate the effectiveness and accuracy of this thermal resistance determination procedure which utilizes the infrared surface thermometers to perform the initial measurements. This work was performed by NBS and sponsored by DOE.

The basic function of an infrared thermometer (henceforth referred to as an IRT) is to indicate the surface temperature of objects or materials. An IRT is a small, light, and frequently gun-shaped device (see Figure 1) which operates by detecting infrared radiation emitted and reflected from a surface. Performing a measurement is accomplished by pointing the IRT at the surface of interest and depressing the on-off trigger of the device. The infrared radiation received by the IRT is converted into an electrical signal which is amplified by solid-state circuitry and subsequently processed through compensation circuitry to a meter which is calibrated to indicate surface temperature direetly.

Typical specifications for IRT's include a temperature measurement resolution within $\pm 0.5^{\circ} \mathrm{F}$, an indoor temperature range of $50^{\circ} \mathrm{F}$ to $100^{\circ} \mathrm{F}$, an outdoor temperature range of $-20^{\circ} \mathrm{F}$ to $130^{\circ} \mathrm{F}$, a spectral response in the range of $10 \mathrm{microns,}$ and a response time of less than 2 seconds. Since contact with the surface to be measured is not necessary with these devices, it is possible not only to minimize the error due to disturbing the thermal regime of the subject surface, but also to determine the surface temperature of otherwise inaccessible objects, such as secondstory walls. The target size increases with increasing distance from the object to the instrument at a ratio of 1 -inch diameter target per each 15-inch operating distance. The IRT indicates an average temperature for the surface being measured over the entire field of view. Therefore, operation close to a wall will indicate surface temperature of a small region, while operation at a distance will indicate surface temperature for a larger region. 


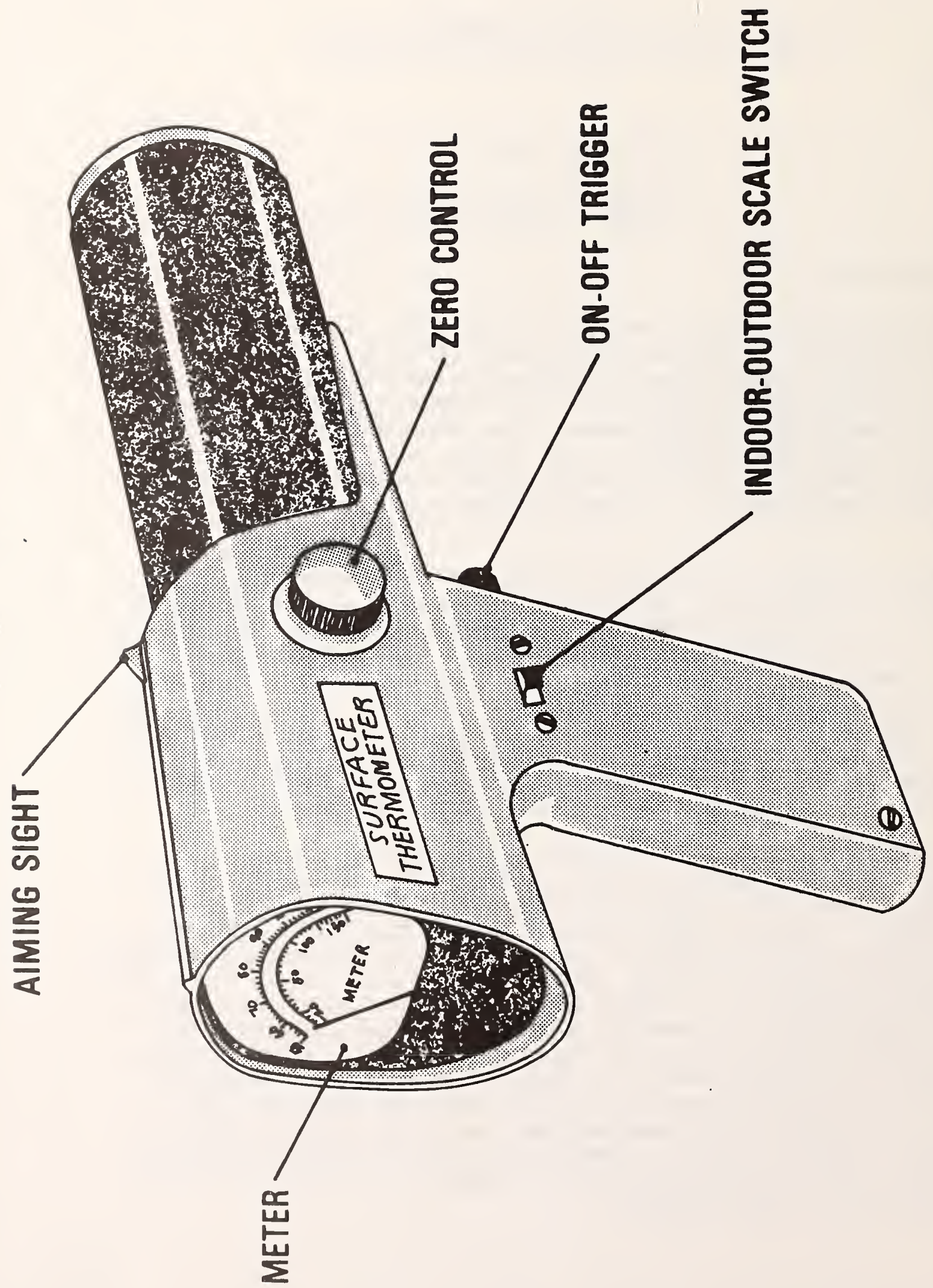


IRT's are utilized widely for various temperature measurement applications and qualitative investigations of the thermal properties of buildings. The IRT's are also currently used to provide temperature measurements as part of a technique for determining the thermal resistances of walls. This technique has been utilized by utility companies, insulation contractors and other individuals during energy audit studies or sales programs, and consists of the procedure described below.

Several questions exist as to the reliability of the thermal resistance determination procedure. These include the effect of dynamic (nonsteady) conditions, temperature measurement accuracy, and uncertainty in specifying the surface heat-transfer coefficient, the value of which is dependent upon air flow along the surface as well as radiative heat exchange between the surface and the surrounding surfaces that see the subject surface.

\section{THERMAL RESISTANCE DETERMINATION TECHNIQUE}

In the current practice, the thermal resistance of an exterior wall is determined by measuring the interior air temperature, the interior surface temperature of the wall and the exterior surface temperature of the wa11. These three measured temperatures are then substituted into an equation relating heat flow through the exterior wall to the interior surface-to-air temperature difference and the temperature differential between the interior-to-exterior wall surfaces. This equation is based on a steady-state model of heat flow through a wall, and utilizes assumed values for the interior surface heat-transfer coefficient and the surface emittance of the interior side of the wall.

In actual practice, the manufacturers of the IRT devices recommend that the interior air temperature be determined by measuring the surface temperature of a piece of furniture, followed by direct temperature measurements of the interior and exterior surfaces of the wall in question. The attractive features of this technique are ease in operation, fast response and portable operation in the nondestructive determination of the thermal resistance of walls. If validated, a simple and fast thermal resistance determination technique such as this could be of significant value in aiding energy conservation and thermal analysis programs. The purpose of this paper is to evaluate the accuracy and reliability of the IRT technique in determining bullding envelope thermal resistance.

1 Stainton, W.D., Heat Transfer and Building Surface Temperatures, IRIE Conference Transaction (in preparation) 1978. 
Consider the exterior wall schematic shown in Figure 2.

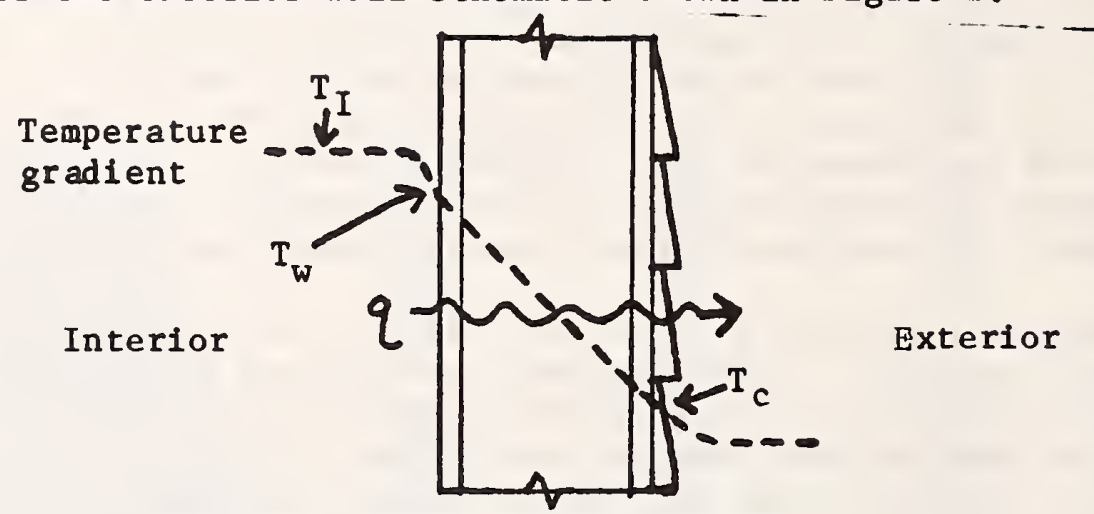

Figure 2. Exterior wall schematic

The instantaneous heat-loss rate $(q)$ at the inside surface is given by

$$
\mathrm{q}=\mathrm{f}_{\mathrm{I}} \cdot\left(\mathrm{T}_{\mathrm{I}}-\mathrm{T}_{\mathrm{w}}\right)
$$

where $f_{I}=$ overall heat-transfer coefficient at the inside

$$
\begin{gathered}
\quad \text { surface, } \frac{\mathrm{Btu}}{\mathrm{h} \cdot \mathrm{ft}^{2 \cdot{ }^{\circ} \mathrm{F}}} \\
\mathrm{T}_{\mathrm{I}}=\text { interior air temperature, }{ }^{\circ} \mathrm{F} \\
\mathrm{T}_{\mathrm{W}}=\text { interior surface temperature, }{ }^{\circ} \mathrm{F}
\end{gathered}
$$

Under steady-state conditions, the heat-loss rate through the wall may also be determined using the relation:

$$
q=\left(T_{w}-T_{c}\right) / R
$$

where $\quad R=$ surface-to-surface thermal resistance, $\frac{{ }^{\circ} \mathrm{F} \cdot \mathrm{h} \cdot \mathrm{ft}^{2}}{\mathrm{Btu}}$

$$
\mathrm{T}_{\mathrm{C}}=\text { exterior surface temperature, }{ }^{\circ} \mathrm{F} \text {. }
$$

Under steady-state conditions, we may combine eqns. (1) and (2) to give:

$$
R=\frac{\left(T_{w}-T_{c}\right)}{\mathrm{f}_{\mathrm{I}} \cdot\left(\mathrm{T}_{\mathrm{I}}-\mathrm{T}_{\mathrm{w}}\right)}
$$

If this model is valid, the surface-to-surface thermal resistance of an exterior wall can be determined based on the three pertinent temperature measurements, together with an assumed value for the interior surface heat-transfer coefficient. 
The basic issue examined in this paper is the accuracy of the method described in the previous section for determining wall thermal resistance. In addition, the temperature measurement accuracy of the IRT's is examined, along with comparison thermal resistance determinations obtained through the use of thermopiles and heat-flow meters.

Temperature measurements and the related thermal resistance determinations were performed in the laboratory for a wood-frame wall and in the field for a wood-frame brick veneer wall. One half of the wall cavities in the laboratory wall were insulated with loose-fill cellulose, while the remaining half were uninsulated. Sets of measurements were made at various temperature conditions under both steady-state and dynamic conditions utilizing the IRT's and alternate technqiues. The range of thermal resistance values determined from these measurements were then compared to the calculated thermal resistance (based on ASHRAE Handbook values) of the wall in question.

An error analysis was also performed, examining the parameters which affect the accuracy of the thermal resistance determination procedure utilizing an IRT.

\section{LABORATORY TEST}

\subsection{INSTRUMENTATION AND TEST SET-UP}

The first stage of the test involved laboratory measurements on a typically constructed wood-frame wall composed of $2 \times 4$ studs ( 16 in. on center), 1/2-in. gypsum board, wood-fiber sheathing and redwood siding. One half of the wall cavities contained loose-fill cellulose insulation while the remaining half contained no added insulation. The computed thermal resistances for the insulated and uninsulated portions of the wall were 15.2 and $4.2^{\circ} \mathrm{F}^{\bullet} \mathrm{h}^{\bullet} \mathrm{ft}^{2}$ respectively. (See Table 1 for computation.) Btu

The test wall was placed between two temperature controlled chambers (see Figure 3), and subjected to various combinations of simulated indoor and outdoor conditions. Measurements were performed under both steadystate and dynamic (non-steady) conditions. Both the insulated and the uninsulated portions of the wall were instrumented identically. Four heat-flow meters were connected in series and spot glued to the interior surface at the center of each portion of the wall. Each of the heatflow meters consisted of a thin cylindrical wafer containing an imbedded thermopile previously calibrated by the guarded-hot-plate apparatus. The millivolt signal generated from the thermopile is proportional to the heat flow passing through the wafer. In addition, two thermopiles, each with three pairs of junctions, were installed on each portion of the wall to indicate surface-to-air and surface-to-surface temperature differences (see Figure 3). Each set of heat-flow meters was connected 

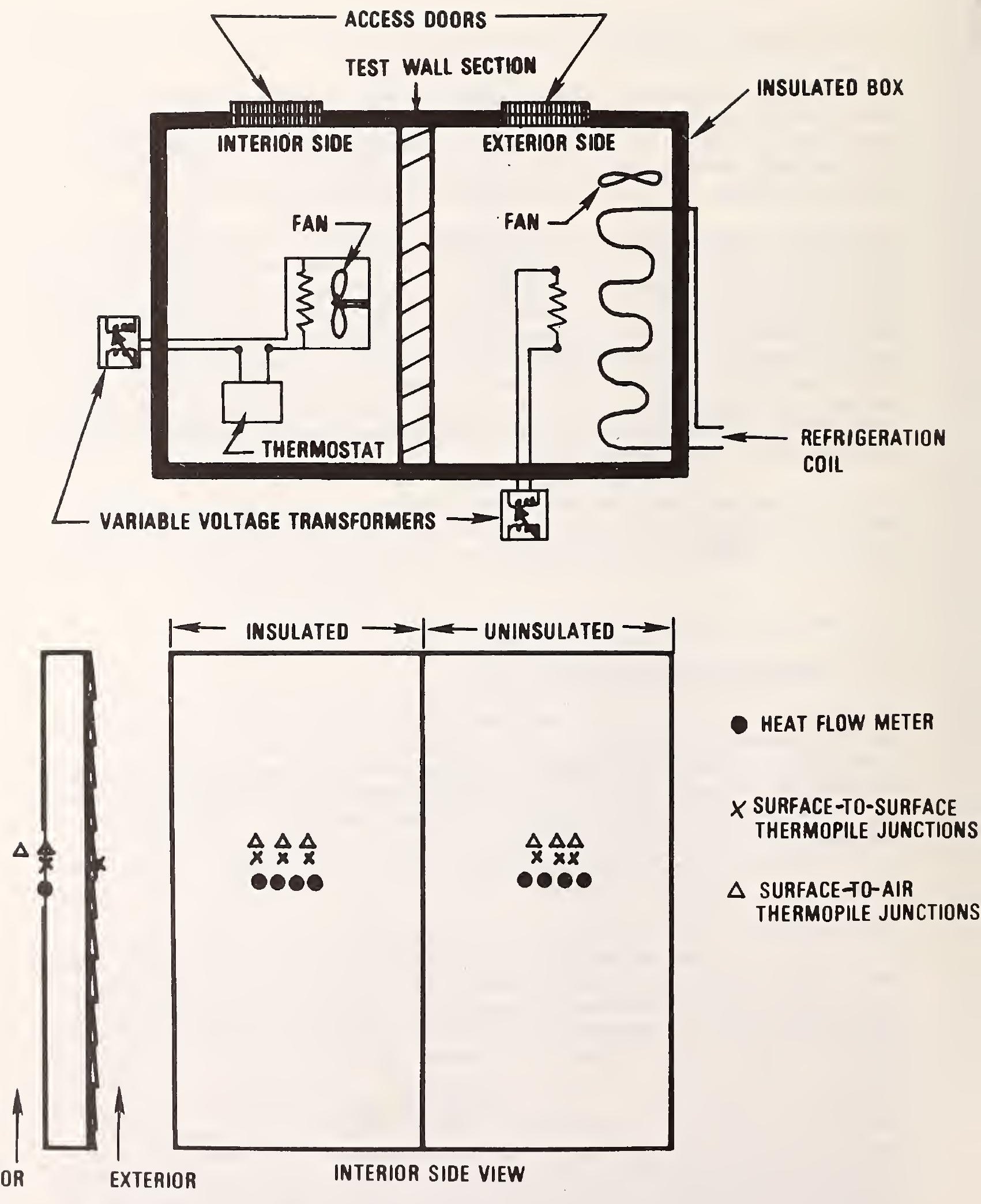

Figure 3. Schematic of Laboratory Set-up. 
TABLE 1. THERMAL RESISTANCE VALUES

\begin{tabular}{lcc} 
Material & $\begin{array}{c}\text { Thickness } \\
\text { in. }\end{array}$ & $\begin{array}{c}\text { Thermal Resistance* } \\
\frac{{ }^{\circ} \mathrm{F} \cdot \mathrm{h} \cdot \mathrm{ft}^{2}}{\mathrm{Btu}}\end{array}$ \\
\hline Gypsum Board & 0.5 & 0.35 \\
Cellulose & 3.5 & 11.99 \\
Wood-fiber sheathing & 0.75 & 1.95 \\
Redwood Siding & 0.75 & 0.89 \\
Air Space & 3.5 & 0.97 \\
\hline & & \\
Rinsulated $=0.35+11.99+1.95+0.89=15.18 \approx 15.2 \frac{{ }^{\circ} \mathrm{F} \cdot \mathrm{h} \cdot \mathrm{ft}^{2}}{\mathrm{Btu}}$
\end{tabular}

*

Based on ASHRAE Handbook values.

to an analog integrator for the purpose of averaging the signal over a five-minute period to minimize the error due to random surface temperature fluctuations, especially when readings are to be made at conditions of low temperature differences. Similarly, each thermopile was connected to its own integrator. Thermocouples were also installed to indicate surface and air temperatures on the interior and exterior sides of the wall. These sensors were connected to a data acquisition system which recorded their signal levels automatically every hour and manually before each thermal resistance determination.

To simulate winter conditions, the portion of the box surrounding the exterior side of the wall was cooled with a specially designed refrigeration system. The main features of the system are a large evaporation tank and a force-feed flooded coil, which was installed inside the box.

Air within the chamber was cooled by passing it over the coil with a fan. Temperature control was accomplished through the use of electric heaters within the tank. The portion of the box surrounding the interior side of the wall was heated with a thermostatically controlled electricresistance heater which operated in conjunction with a small fan to provide air circulation within the chamber. The voltage supplied to the heater was controlled with a variable transformer to enable the precise control of the cycling period needed to retain a steady-state temperature condition regardless of the exterior condition.

For the purpose of providing dynamic test conditions, temperature fluctuations on the exterior side were accomplished through the addition of 
electric heat on a time scale designed to simulate typical diurnal temperature cycles. Fluctuating indoor conditions were obtained by increasing the voltage supplied to the heater located within the interior portion of the box, causing the air temperature to vary, simulating the operation of a typical furnace.

\subsection{MEASUREMENT PROCEDURE}

The thermal resistance of the test wall was determined utilizing four different measurement procedures. Each measurement procedure consisted of a series of thermal resistance determinations, at various temperature conditions, utilizing either the IRT's, thermopiles or heat-flow meters. Initial measurements using the IRT's were performed following the manufacturers' instructions explicitly. Under this procedure, each IRT was calibrated with a factory-supplied black reference block upon which a surface thermometer indicated temperature. Calibration was accomplished by aiming the IRT at the reference body and adjusting the IRT zero control until the temperature indicated on the IRT meter matched that of the reference body. The distance-to-size ratio of the IRT's is 15 to 1 , providing a circular target area of $2 \mathrm{in}$. diameter at a distance of $30 \mathrm{in.} \mathrm{A} \mathrm{single} \mathrm{calibration} \mathrm{is} \mathrm{said} \mathrm{by} \mathrm{the} \mathrm{manufacturers} \mathrm{to} \mathrm{be} \mathrm{suffi-}$ cient to enable accurate temperature measurements to be made using either the indoor or outdoor scale of the IRT. This procedure will henceforth be referred to as the "manufacturer's calibration procedure." Following this procedure, indoor air temperature was measured by determining the surface temperature of a piece of foam insulation which was located within the "indoor" side of the chamber. Wall surface temperatures were then determined at points of the same height on both the insulated and uninsulated portions of the wall.

The second procedure utilized was similar to the manufacturer's calibration procedure with the exception that separate calibrations were performed on the IRT's before both the interior and exterior measurements. Copper sheets painted flat black were installed in both the interior and exterior chamber portions, each with a thermocouple soldered to its surface. Calibrations were performed using these sheets as references prior to each measurement. This procedure will henceforth be referred to as the "laboratory calibration procedure".

Additional measurements were made through the use of the two pairs of thermopiles to indicate the temperature differences between the indoor surface and the indoor air and between the indoor and outdoor surfaces. This procedure was designed to demonstrate the accuracy in determining thermal resistance which would be expected from a device which could measure surface temperature differences with an accuracy of within $\pm 0.3^{\circ} \mathrm{F}$, approximately twice the specified temperature difference measurement accuracy of the IRT's.

The fourth measurement procedure consisted of thermal resistance values obtained by dividing the surface-to-surface temperature difference across 
the wall as measured by thermopiles into the heat flow through the wall as measured by heat-flow meters.

\subsection{EXPERIMENTAL RESULTS}

Table 2 gives the range of thermal resistance values determined during the laboratory phase of the testing. The left hand column indicates the temperature conditions under either steady-state or dynamic conditions. Several sets of measurements were usually performed at each temperature condition. A range of thermal resistance values is given for each of the four different procedures. The values listed are the individual lower and upper thermal resistance determinations; other values lie within this range.

Considerable variation was observed between different thermal resistance determinations using the IRT's at the same temperature conditions, as shown in Table 2 expressed in $\frac{{ }^{\circ} \mathrm{F} \cdot \mathrm{h} \cdot \mathrm{ft}^{2}}{\mathrm{Btu}}$. Errors were larger for the

insulated portion of the wall, with thermal resistance determination values as high as 42.5 and as 1 ow as 11.8 under steady-state conditions, and as high as 58.7 and as low as 12.8 under dynamic conditions, compared to the calculated value of 15.2. Errors in the thermal resistance determinations for the uninsulated portion of the wall were smaller, but significant variation still occurred, especially under dynamic conditions where values ranged as low as 2.2 and as high as 6.6 compared to the calculated value of 4.2 .

During the testing, a significant difference was observed between the thermal resistances determined for the insulated and uninsulated portions of the wall. Under the coldest conditions, some of the temperature measurements by the IRT's were erroneously off-scale, preventing determination of the thermal resistance under those conditions. Improved accuracy resulted when the laboratory calibration procedure was used instead of the manufacturers' calibration procedure.

The values obtained utilizing the thermopiles demonstrate the accuracy expected with a more accurate temperature measurement system. If the IRT's were as accurate as the thermopiles in determining surface temperatures, their accuracy in determining thermal resistance would be approximately the same as that of the thermopile system. Thermal resistance determinations utilizing the thermopiles are seen to exhibit less variation and greater accuracy than those obtained through the use of the IRT's. The overall range of thermal resistance values is seen to extend from 9.6 to 23.6 for the insulated portion of the wall, and between 4.5 and 6.6 for the uninsulated portion of the wall. Since greater accuracy is obtained through the use of the thermopile system, inaccuracies in temperature measurements with the IRT's are partially responsible for errors in thermal resistance determinations. 
TABLE 2. LABORATORY THERMAL RESISTANCE DETERMINATIONS

Test Condition, ${ }^{\circ} \mathrm{F} \quad$ Thermal Resistance Range ${ }^{1} \frac{{ }^{\circ} \mathrm{F}^{\bullet} \mathrm{h}^{\bullet} \mathrm{ft}^{2}}{\mathrm{Btu}}$

IR Thermometer

Thermopile

Heat-Flow Meter Thermopile

Interior Exterior Mfgrs. Calib. Lab Calib. For Insulated Wall $\mathrm{R}=15.2$

Steady-State

$\begin{array}{llcccr}75 & 10 & 19.7-40.6 * & 18.2-25.0 & 15.0 & 14.3 \\ 75 & 45 & 16.9-28.3 & -- & 15.4-17.5 & 21.5 \\ 73 & 33 & 23.1-42.5 & 26.0-27.6 & 15.1 & -- \\ 78 & 88 & 11.8-17.9 * & --- & -- & --\end{array}$

Dynamic

$\begin{array}{cccccr}75 & 10-43 & 25.7-33.9 & -- & -- & -- \\ 75 & 42-25 & 31.3-40.9 & 22.1-37.8 & 23.6 & -- \\ 73-78 & 33 & 12.8-37.0 & 6.3-27.6 & 9.6-11.3 & --- \\ 75 & 30-60 & 22.8-58.7 & 18.1-18.9 & 15.2 & 13.4\end{array}$

For Uninsulated Wall $R=4.2$

Steady-State

$\begin{array}{lllccc}75 & 10 & 3.8-5.1^{*} & 2.5-3.0 & 4.5 & 4.7 \\ 75 & 45 & 2.8-4.2 & -- & 5.4-6.0 & 5.1 \\ 73 & 33 & 3.0-4.8 & 2.4-2.6 & 5.0-5.6 & \ldots- \\ 78 & 88 & 3.2-4.6 & -\ldots & -- & -\ldots\end{array}$

Dynamic

$\begin{array}{cccccc}75 & 10-43 & 3.3-3.8 & -- & -- & -- \\ 75 & 42-25 & 4.6-6.6 & 3.1-4.2 & 5.2-6.6 & -- \\ 73-78 & 33 & 3.0-3.7 & 2.1-2.8 & 4.5-4.9 & - \\ 75 & 30-60 & 2.2-3.5 & 1.4-1.9 & 4.7 & 4.5\end{array}$

1 Thermal resistance values are based on measurements and do not include air film resistances.

Fifty percent of the temperature measurements at this condition were offscale or unmeasurable, making it impossible to determine thermal resistance. 
The heat-flow meter thermopile combination was subjected to limited testing, but accuracy observed was comparable to that using the thermopiles alone.

\section{FIELD TEST}

\subsection{INSTRUMENTATION AND TEST SET-UP}

The second stage of the test involved field measurements of an exterior wall of a townhouse. The structure tested was a typically constructed two-story unit built on a slab-on-grade (see Fig. 4). The particular wall tested was comprised of 3/8-in. wood paneling, $2 \times 4$ wood framing, and 1/2-in. wood-fiber sheathing with a brick-veneer exterior surface. The wall cavities contained 3-1/2-in. glass-fiber insulation. The computed thermal resistance for the portions of the wall not containing studs is 13.2 (see Table 3 for computation).

\section{TABLE 3. THERMAL RESISTANCE VALUES}

Thermal Resistance*

\begin{tabular}{|c|c|c|}
\hline Material & $\begin{array}{c}\text { Thickness } \\
\text { in. }\end{array}$ & $\frac{{ }^{\circ} \mathrm{F} \cdot \mathrm{h} \cdot \mathrm{ft}^{2}}{\mathrm{Btu}}$ \\
\hline Wood Paneling & 0.375 & 0.47 \\
\hline Glass Fiber & 3.5 & 11.0 \\
\hline Wood-Fiber Sheathing & 0.5 & $1 \cdot 32$ \\
\hline Brick & 3.5 & 0.39 \\
\hline
\end{tabular}

This wall was instrumented in a fashion similar to the laboratory setup, with thermopiles to indicate temperature differentials, thermocouples to indicate surface and air temperatures, and a heat-flow meter. Normal thermostatic operation of the gas-fired forced-air furnace was utilized.

\subsection{MEASUREMENT PROCEDURE}

The measurement procedure utilized during the field portion of the test was essentially the same as used during the laboratory phase. In addition to the manufacturers' and laboratory calibration procedures described in the laboratory measurement procedure section, a third 


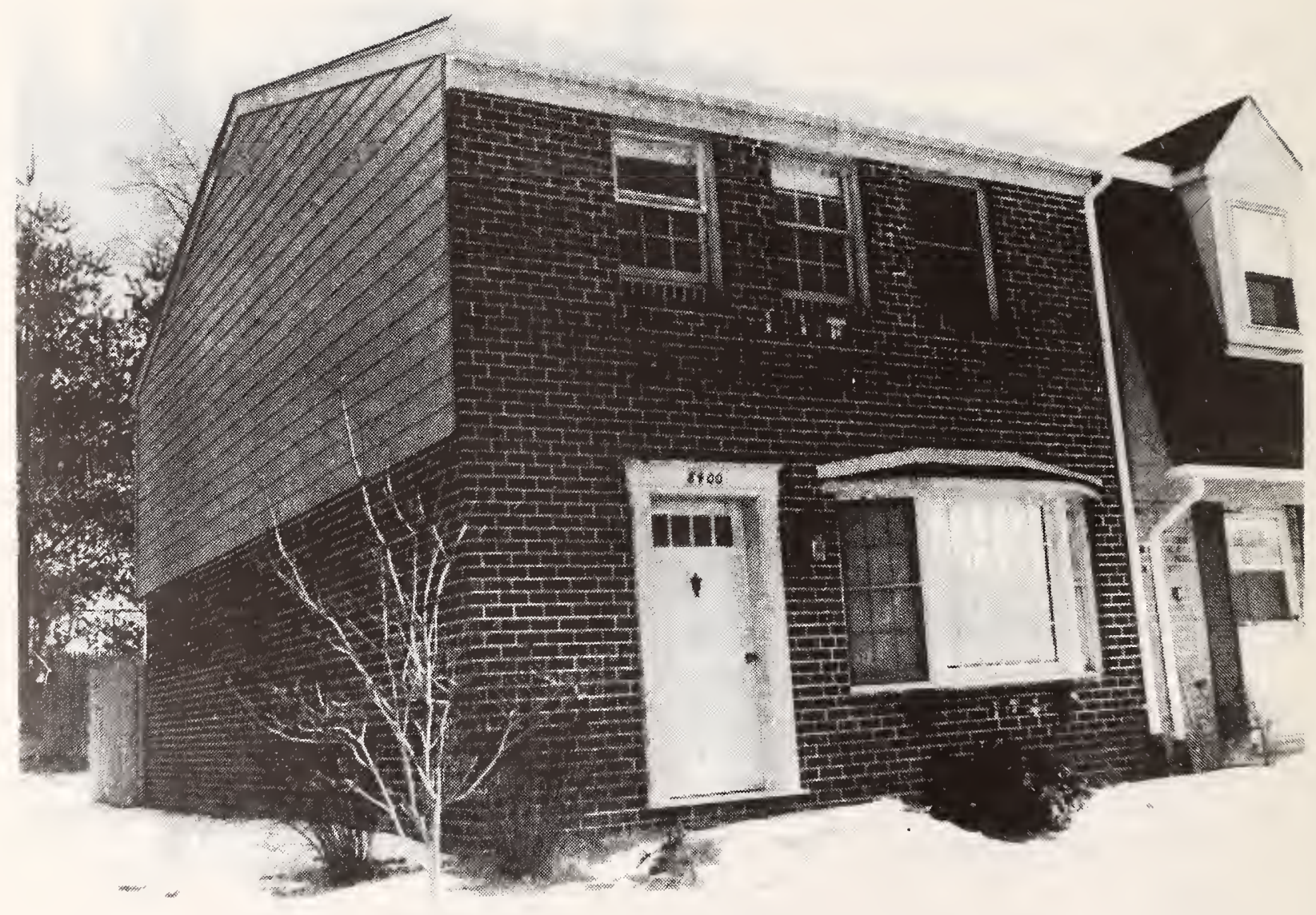

Figure 4. Photograph of the Test House. 
calibration procedure was used. This third procedure was called the alternate calibration procedure and utilized a foam insulation board, instrumented with a surface thermocouple, as a calibration standard. Following this procedure, the insulation board was substituted for the reference block supplied by the manufacturers and a single calibration was performed as per the manufacturers calibration procedure. This procedure was used because of observed inaccuracies in the calibration standards provided by the IRT manufacturers.

\subsection{EXPERIMENTAL RESULTS}

Table 4 contains a compilation of the results of the field tests of a wood-frame brick-veneer wall. The indoor air temperature listed is the average value of the actual temperature which varied with thermostatic operation of the furnace.

$$
\begin{aligned}
& \text { TABLE 4. FIELD THERMAL RESISTANCE DETERMINATIONS } \\
& \text { FOR WOOD-FRAME BRICK VENEER WALL } \mathrm{R}=13.2 \frac{{ }^{\circ} \mathrm{F} \cdot \mathrm{h} \cdot \mathrm{ft}^{2}}{\mathrm{Btu}}
\end{aligned}
$$

Test Condition, ${ }^{\circ} \mathrm{F} \quad$ Thermal Resistance Range ${ }^{1} \frac{{ }^{\circ} \mathrm{F}^{\bullet} \mathrm{h}^{\bullet} \mathrm{ft}^{2}}{\mathrm{Btu}}$

Interior Exterior Device A Device B Device C Thermopile

Mfgrs.

Calib.
$73.5 \quad 28.0$
$20.4-99.4$
$30.3-65.4$
$2.5-16.7$

Alternate

Calib.
$74 \cdot 0$
29.0
$8.0-9.8$
$11.9-18.5$
$5.1-7.9$

Lab.

Calib.
74.0
29.0
$7.6-13.6$
$9.6-13.6$
$8.4-12.9$

1 Thermal resistance values are based on measurements and do not include air film resistances.

Devices A and B were the same IRT's used during the laboratory phase of the test. Device $C$, which was received late in the testing schedule and subjected to a limited test regime, was a self-calibrating IRT made 
by the same company that supplied one of the other IRT's, and was otherwise similar to the other two IRT's.

Thermal resistance determinations are listed for the three different calibration procedures for the IRT's. Considerable variation is seen for the values obtained using the manufacturer's calibration procedure, with a range of thermal resistance determination values between 20.4 and 99.4, compared to a calculated value of 13.2. Utilization of the alternate or lab calibration greatly reduced the error in the thermal resistance determinations, but significant variations are still seen to occur.

\section{ANALYSIS}

Examination of the data reveals several major points. All of the IRT's except the self-calibrating one experienced difficulty in accurately measuring low temperatures. Error increased with decreasing temperature, as indicated in Table 2. This problem may be due to several factors. The cold temperatures may affect the electronics of the instruments, altering their response characteristics. The manufacturers recommend making cold temperature measurements as quickly as possible -- a technique which was utilized throughout this test. As an example of lowtemperature measurement difficulities, attempts to measure an exterior wall surface at a temperature of $32^{\circ} \mathrm{F}$ resulted in temperature readings ranging from $26^{\circ} \mathrm{F}$ to $-20^{\circ} \mathrm{F}$. The magnitude of the low-temperature measurement inaccuracy varied between different IRT's. Inaccuracies in calibration may also strongly affect cold temperature measurements. This possibility is supported by the significant improvement in measurement accuracy observed during the field tests utilizing a more accurate calibration method rather than the manufacturers' calibration procedure.

Separate indoor and outdoor calibrations improved the accuracy of the temperature measurements but had less effect on the accuracy of the thermal resistance values. Since the thermal resistance calculation is essentially dependent upon temperature differences, a tradeoff exists between improving the accuracy of the individual temperature measurement on the cold side and disrupting the internal consistency of the instrument. In other words, if an IRT is reading slightly low due to inaccurate calibration, the measured temperature difference may not be as inaccurate as the temperature difference obtained after separate calibrations, because the effect of the inaccurate temperature measurements will tend to cancel out when computing the temperature difference.

The most serious disadvantage of the measuring system concerns the transients which are apparent under almost all natural conditions. Intermittent sunlight, wind, thermostatic operation of the furnace, and outdoor temperature conditions all contribute to this problem. The thermal resistance of a wall is not a simple function of instantaneous heat flow and temperature difference except under steady-state conditions. An 
example of this concept is illustrated in Figure 5. The indoor surfaceto-air temperature difference is seen to vary by almost $8{ }^{\circ} \mathrm{F}$ in response to the furnace cycle. A smaller effect is seen in the surface-to-surface differential measurement. The instantaneous thermal resistance computed following the model utilized by the IRT measurement technique indicates values ranging from 2 to 50 over a one-hour period. Since the air temperature is actually measured by determining the surface temperature of a plece of furniture rather than the true air temperature, large changes in air temperature over short time periods will be smoothed out due to the thermal mass of the piece of furniture, lessening the fluctuations in the surface-to-air temperature difference.

Other factors also affect the accuracy of the measurements. Consider an insulated wall $(R=15)$ and an uninsulated wall $(R=5)$. If these walls are exposed to a $40^{\circ} \mathrm{F}$ inside-to-outside temperature difference, the resulting heat-flow rates as given by eq. (2) are $2.7 \mathrm{Btu} / \mathrm{h} \bullet \mathrm{ft}^{2}$ for an insulated wall and $8 \mathrm{Btu} / \mathrm{h} \cdot \mathrm{ft}^{2}$ for an uninsulated wall. A representative value for the inside heat-transfer coefficient is $1.2 \mathrm{Btu} / \mathrm{h} \cdot \mathrm{ft} \mathrm{f}^{2} \cdot{ }^{\circ} \mathrm{F}$ (see text below). Using eq (1), the air-to-surface temperature difference $\left(T_{1}-T_{w}\right)$ is estimated to be $2.3^{\circ} \mathrm{F}$ for an insulated wall and $6.8^{\circ} \mathrm{F}$ for an uninsulated wall.

The manufacturers' literature on IRT's states that temperatures can be measured to within $\pm 0.5^{\circ} \mathrm{F}$. Using these tolerances, the maximum uncertainty in measuring $\left(T_{1}-T_{w}\right)$ and $\left(T_{W}-T_{C}\right)$ is $\pm_{1}^{\circ} F$. Hence, the percent error in estimating $\left(\mathrm{T}_{1}-\mathrm{T}_{\mathrm{W}}\right)$ is $1.0 / 2.3=4 \overline{3} \%$ for an insulated wall and $1.0 / 6.8=15 \%$ for an uninsulated wall. In the case of the overall temperature difference across the wall $\left(T_{W}-T_{c}\right)$, the percent error is $1 / 40=2.5 \%$.

The inside surface heat transfer coefficient consists of both radiative and convective components. The radiative component $\left(\mathrm{f}_{\mathrm{r}}\right.$ ) may be estimated by the relation:

$$
\mathrm{f}_{\mathrm{r}}=4 \cdot \sigma \cdot \mathrm{ET}_{\mathrm{MRT}}^{3}
$$

where $\sigma=$ Stefan-Boltzmann constant

$E=$ emittance factor, $E=\frac{1}{1 / e_{1}+1 / e_{2}-1}$

$e_{1}=$ interior surface emittance of wall

$e_{2}=$ emittance of the surrounding surfaces

$\mathrm{T}_{\mathrm{MRT}}=$ absolute mean-radiant temperature of the room.

Under typical indoor conditions, a representative value for $f_{r}$ is $0.88 \mathrm{Btu} / \mathrm{h} \cdot \mathrm{ft}^{2}{ }^{\circ} \mathrm{F}$.

The convective component of the overall surface heat-transfer coefficient is a complex function of the surface-to-air temperature difference, largescale convective air movement patterns present in a room, and the height above the floor. In the absence of large-scale convective air movement, 


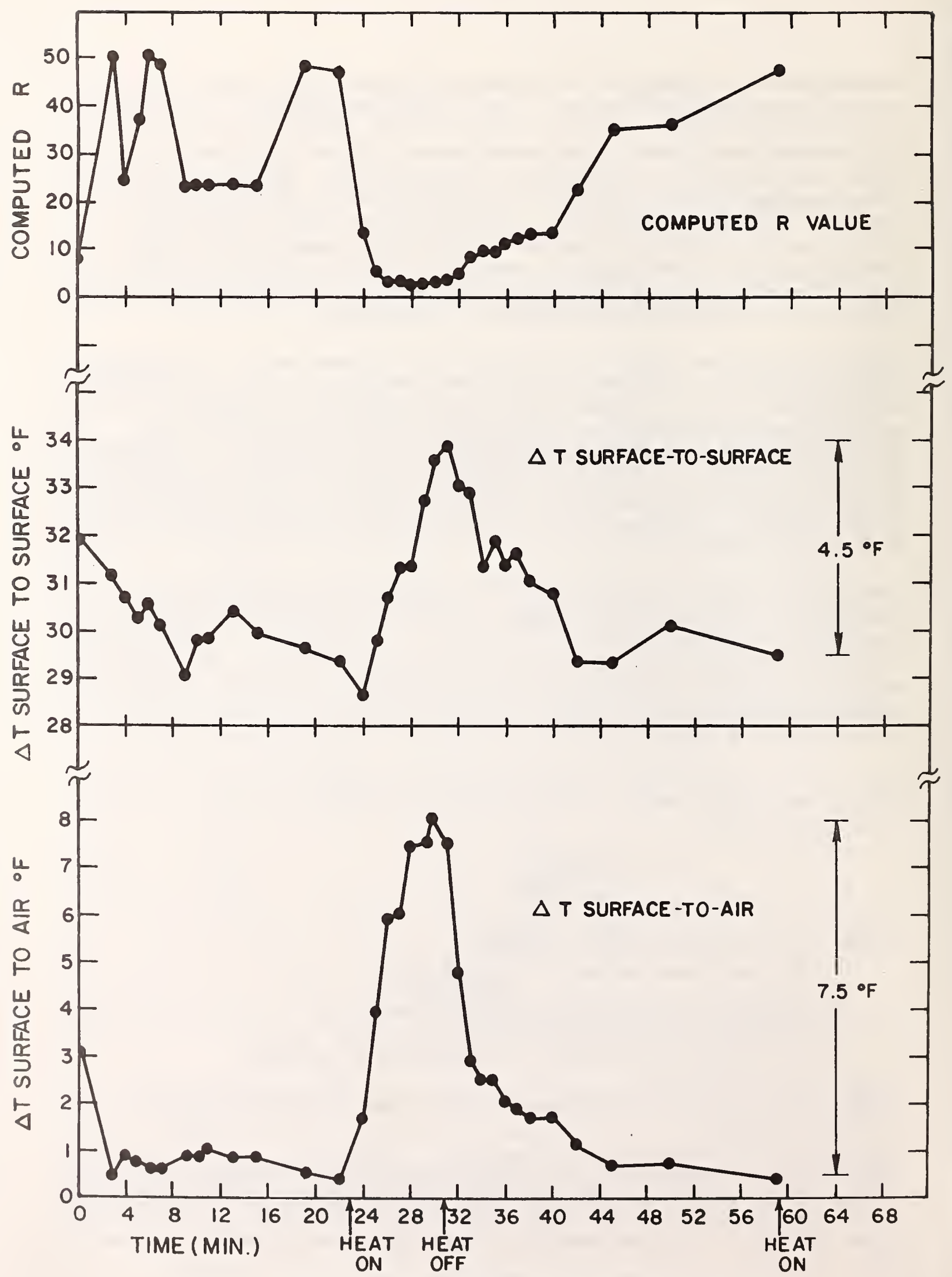

Figure 5. Thermal Resistance Values under Dynamic Conditions. 
a laminar free-convection boundary layer will exist at the top of the wall. This boundary layer will grow in size, passing through a transition region, and then turn into a turbulent boundary layer further down the wall. Generally, the convective component will vary between 0.2 to $0.4 \mathrm{Btu} / \mathrm{h} \cdot \mathrm{ft}^{2}{ }^{\circ} \mathrm{F}$, so that the uncertainty in specifying the convective component of the overall surface heat-transfer coefficient is \pm 0.2 $\mathrm{Btu} / \mathrm{h} \cdot \mathrm{ft}^{2} \cdot{ }^{\circ} \mathrm{F}$ or $\pm 17 \%$.

The uncertainties in specifying $f_{I}$ and in measuring $\left(T_{1}-T_{W}\right)$ and $\left(T_{W}-T_{C}\right)$ are summarized in $T_{a b l e} 5$.

TABLE 5. SUMMARY OF UNCERTAINTIES IN MEASURING THE THERMAL RESISTANCE OF AN INSULATED WALL

\begin{tabular}{ccc}
\hline & \multicolumn{1}{c}{ Uncertainty } \\
\cline { 2 - 3 } & \multicolumn{1}{c}{$\begin{array}{c}\text { Normal } \\
\text { Range }\end{array}$} \\
\hline $\mathrm{f}_{\mathrm{I}}$ & $\pm 0.2 \mathrm{Btu} / \mathrm{h} \cdot \mathrm{ft}^{2}{ }^{\circ}{ }^{\circ} \mathrm{F}$ & $\pm 17 \%$ \\
$\mathrm{~T}_{\mathrm{I}}-\mathrm{T}_{\mathrm{W}}$ & $\pm 1.0{ }^{\circ} \mathrm{F}$ & $\pm 43 \%$ \\
$\mathrm{~T}_{\mathrm{W}}-\mathrm{T}_{\mathrm{C}}$ & $\pm 1.0{ }^{\circ} \mathrm{F}$ & $\pm 2.5 \%$
\end{tabular}

$\mathrm{Ku}^{2}$ has presented propagation of error formulas for some simple functions. For the function form $M_{w}=M_{x} \cdot M_{y}$, the variance $\left(S_{w}^{2}\right)$ is given by:

$$
s_{w}^{2}=(\bar{x} \bar{y})^{2} \quad \cdot\left\{\begin{array}{l}
s_{\bar{x}}^{2}+s_{\bar{y}}^{2} \\
\bar{x} \\
\bar{x}
\end{array}\right\}
$$

where $\bar{x}=$ mean value of $x$

$$
\begin{aligned}
\bar{y} & =\text { mean value of } y \\
s_{\bar{x}}^{2} & =\text { variance of } x \\
s_{\bar{y}}^{2} & =\text { variance of } y
\end{aligned}
$$

2 H. H. Ku, "Statistical Concepts in Metrology", Handbook of Industrial Metrology, American Society of Tool and Manufacturing Engineers, pp. 20-50, Prentice-Hall, Inc., New York, 1967. 
For the function form $M_{a}=M_{z} / M_{w}$, the variance $\left(S_{a}^{2}\right)$ is given by

$$
s_{a}^{2}=\left(\frac{\bar{z}}{\bar{w}}\right) \cdot\left\{\frac{s_{\bar{z}}^{2}}{\bar{z}^{2}}+\frac{s_{\bar{w}}^{2}}{\bar{w}^{2}}\right\}
$$

where $\bar{z}=$ mean value of $z$

$$
\vec{w}=\text { mean value of } w
$$

$$
\begin{aligned}
& s_{\bar{z}}^{2}=\text { variance of } z \\
& s_{\bar{w}}^{2}=\text { variance of } w
\end{aligned}
$$

A formula for calculating the varlance $\left(S_{R}^{2}\right)$ of the function form $\mathrm{R}=\mathrm{z} /(\mathrm{x} \cdot \mathrm{y})$ may be obtained by combining eqs. (5) and (6) giving the relation:

$$
\frac{S_{R}^{2}}{R^{2}}=\frac{S_{\bar{z}}^{2}}{\bar{z}^{2}}+\frac{S_{\bar{x}}^{2}}{\bar{x}^{2}}+\frac{S_{\bar{y}}^{2}}{\bar{y}^{2}}
$$

The square root of the variance is the standard deviation. If we take 3 standard deviations to constitute the uncertainty $\left(E_{R}\right)$, then we have:

$$
E_{R}=\sqrt{E_{z}^{2}+E_{x}^{2}+E_{y}^{2}}
$$

Substituting the uncertainty values from Table 5 into eq. (8), we find that the uncertainty in the parameters $f_{I},\left(T_{T}-T_{W}\right)$, and $\left(T_{W}-T_{c}\right)$ causes an uncertainty in thermal resistance $(R)$ of $46 \%$ for an insulated wall.

In the case of an uninsulated wall, the surface-to-air temperature difference $\left(T_{I}-T_{W}\right)$ is larger and the unceratinty in $\left(T_{1}-T_{w}\right)$ is $15 \%$. The uncertainty of the other parameters remains the same. Using eq. (8), an uncertainty in $R$ due to the uncertainties of the parameters $F_{I}$, $\left(T_{I}-T_{W}\right)$, and $\left(T_{W}-T_{c}\right)$ is found to be $23 \%$.

\section{SUMMARY}

The technique utilizing hand-held infrared thermometers to determine the thermal resistance of walls by measuring the surface temperatures and air temperature as recommended by the manufacturers of IRT devices 
appears to be considerably inaccurate under typical conditions for a residence. Under steady-state conditions, thermal resistance determinations utilizing the IRT's were found to have an average error of more than 50\%. Under dynamic (non-steady) conditions, this error is approximately doubled.

Some of the error in thermal resistance determination using the IRT's is due to inaccurate surface temperature measurement. However, even if the IRT'S were perfect in indicating surface tempertures, substantial error in $R$ determination would occur due to other factors such as uncertainty in the surface heat-transfer coefficient and emissivity, and transients due to cyclic operation of the furnace and outdoor conditions such as temperature and wind.

A suitable application for the hand-held infrared thermometers is as a qualitative measuring device. It should be possible using the IRT's to determine whether or not a wall is insulated or if insulation voids or other thermal leaks are present. Accurate calibration of the IRT devices is essential. Separate indoor and outdoor calibrations should result in increased accuracy. Care should be exercised to minimize uncertainties due to transients. For greatest accuracy, measurements should be made under conditions which produce a 20 to $30^{\circ} \mathrm{F}$ temperature difference across the wall, and the cold-side surface of the wall should be above $32^{\circ} \mathrm{F}$. 


\section{Nomenclature}

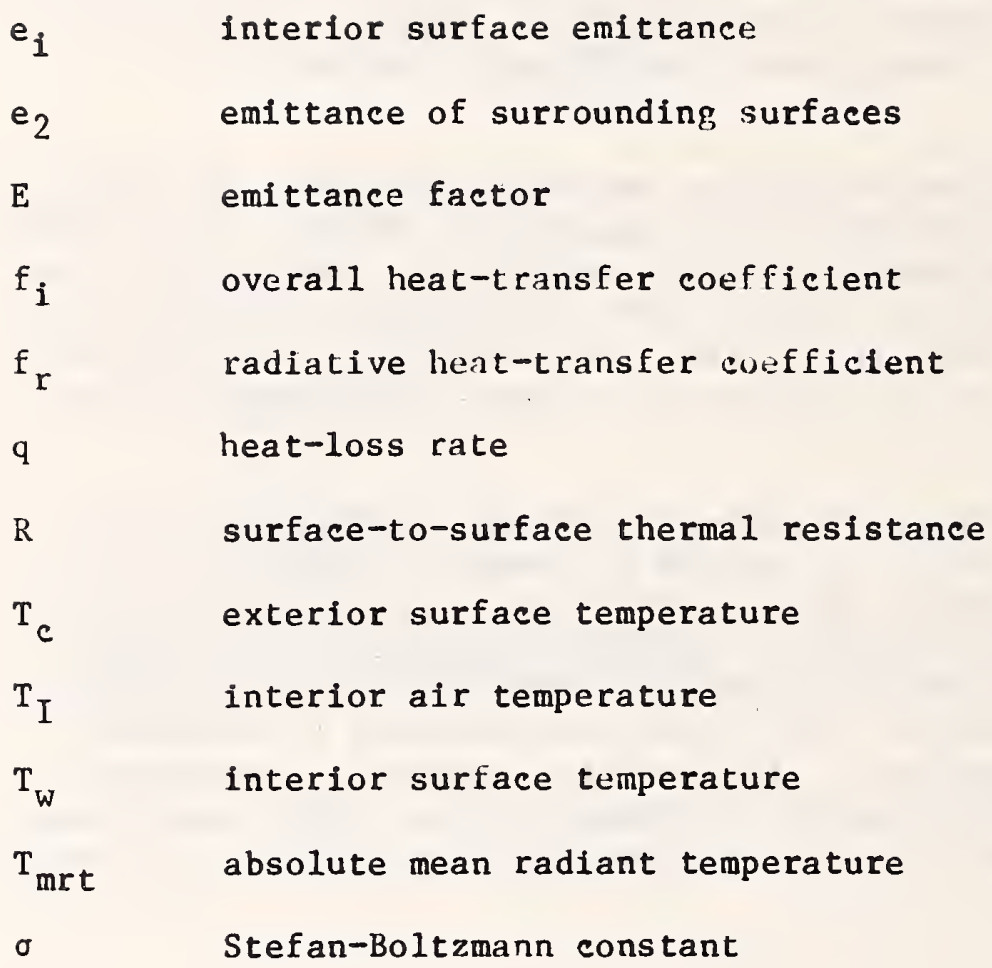


SI Conversion Chart

Physical Quantity

Temperature

Length

Heat Transfer

Thermal Resistance

Heat-Flow Rate
To Convert

From

F

In

$B t u / h \cdot f t^{2} \cdot F$

$h \cdot f t^{2} \cdot F / B t u$

$B t u / h \cdot f t^{2}$
To

C

m

$w / m^{2} \cdot K$

$\mathrm{m}^{2} \cdot \mathrm{k} / \mathrm{w}$

$w / m^{2}$
Multiply by

$T_{c}=\left(T_{F}-32\right) / 1.8$

$2.54\left(10^{-2}\right)$

5.68

$1.76\left(10^{-1}\right)$

3.16 


\begin{tabular}{|c|c|}
\hline $\begin{array}{c}\text { U.S. DEPT. OF COMM. } \\
\text { BIBLIOGRAPHIC DATA } \\
\text { SHEET }\end{array}$ & $\begin{array}{c}\text { 1. PUBLICATION OR REPORT NO. } \\
\text { NBSIR 79-1736 }\end{array}$ \\
\hline
\end{tabular}

4. TITLE AND SUBTITLE

EVALUATION OF HAND-HELD INFRARED THERMOMETERS FOR

WALL THERMAL RESISTANCE DETERMINATIONS

\section{AUTHOR(S)}

Stephen J. Treado and Douglas M. Burch

9. PERFORMING ORGANIZATION NAME AND ADDRESS

\section{NATIONAL BUREAU OF STANDARDS DEPARTMENT OF COMMERCE WASHINGTON, D.C. 20234}

2. Gop't Accession No.
3. Recipient's Accession No.

5. Publication Date

July 1979

6. Performing Organization Code

8. Performing Organ. Report No. 10. Project/Task/Work Unit No. 7422509

11. Contract/Grant No.

12. Sponsoring Organization Name and Complete Address (Street, City, State, ZIP)

Department of Energy

Washington, D. C. 20585

13. Type of Report \& Period Covered

14. Sponsoring Agency Code

15. SUPPLEMENTARY NOTES

16. ABSTRACT (A 200-word or less factual summary of most significant information. If document includes a significant bibliography or literature survey, mention it here.)

Hand-held infrared (IR) non-contact surface thermometers from two manufacturers were tested to evaluate their effectivensss in measuring surface temperatures for the determination of the thermal resistance of walls. Two phases of the test were performed, first a laboratory test of a wood-frame wall, followed by a field test of a brick veneer wood-frame wall. During both phases of testing, additional measurements of thermal resistance were made for comparative purposes, using multijunction thermopiles and heat flow meters. An error analysis of the thermal resistance measurement procedure utilizing IR surface thermometers was also performed.

17. KEY WORDS (six to twelve entries; alphabetical order; capitalize only the first letter of the first key word unless a proper name; separated by semicolons)

Infrared thermometers; in situ evaluation of insulation; R-value measurement by spot radiometer; thermal resistance of walls.

18. AVAILABILITY $\mathrm{X}$ Unlimited

For Official Distribution. Do Not Release to NTIS

Order From Sup. of Doc., U.S. Government Printing Office Washington, D.C. 20402, SD Stock No. SN003-003

Order From National Technical Information Service (NTIS) Springfield, Virginia 22151

\begin{tabular}{|l|c|}
\hline $\begin{array}{l}\text { 19. SECURITY CLASS } \\
\text { (THIS REPURT) }\end{array}$ & 21. NO. OF PAGES \\
UNCL ASSIFIED & 25 \\
\hline $\begin{array}{l}\text { 20. SECURITY CLASS } \\
\text { (THIS PAGE) }\end{array}$ & 22. Price \\
UNCLASSIFIED & $\$ 3.00$ \\
\hline
\end{tabular}





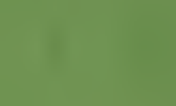

1 